\title{
Isoamericanoic Acid B from Acer tegmentosum as a Potential Phytoestrogen
}

\author{
Seoung Rak Lee ${ }^{1}$, Yong Joo Park ${ }^{1}$, Yu Bin Han ${ }^{1}$, Joo Chan Lee ${ }^{1}$, Seulah Lee ${ }^{1}$, Hyun-Ju Park ${ }^{1}$, \\ Hae-Jeung Lee ${ }^{2, *(1)}$ and Ki Hyun Kim ${ }^{1, *}$ (1) \\ 1 School of Pharmacy, Sungkyunkwan University, Suwon 16419, Korea; davidseoungrak@gmail.com (S.R.L.); \\ pyj084@msn.com (Y.J.P.); youbin1158@hanmail.net (Y.B.H.); leejc3004@gmail.com (J.C.L.); \\ sarahlee0801@gmail.com (S.L.); hyunju85@skku.edu (H.-J.P.) \\ 2 Department of Food and Nutrition, Gachon University, Seongnam 13120, Korea \\ * $\quad$ Correspondence: skysea@gachon.ac.kr (H.-J.L.); khkim83@skku.edu (K.H.K.); Tel.: +82-31-750-5968 (H.-J.L.); \\ $+82-31-290-7700$ (K.H.K.)
}

Received: 15 September 2018; Accepted: 28 November 2018; Published: 4 December 2018

\begin{abstract}
Phytoestrogens derived from plants have attracted the attention of the general public and the medical community due to their potentially beneficial role in relieving menopausal symptoms. The deciduous tree Acer tegmentosum Maxim (Aceraceae) has long been utilized in Korean folk medicine to alleviate many physiological disorders, including abscesses, surgical bleeding, and liver diseases. In order to explore structurally and/or biologically new constituents from Korean medicinal plants, a comprehensive phytochemical study was carried out on the bark of $A$. tegmentosum. One new phenolic compound with a 1,4-benzodioxane scaffold, isoamericanoic acid B (1), as well as with nine known phenolic compounds (2-10), were successfully isolated from the aqueous extracts of the bark of $A$. tegmentosum. A detailed analysis using 1D and 2D NMR spectroscopy, electronic circular dichroism (ECD) spectral data, and LC/MS afforded the unambiguous structural determination of all isolated compounds, including the new compound $\mathbf{1}$. In addition, compounds 2, 4, 5, and 9 were isolated and identified from the bark of A. tegmentosum for the first time. All isolated compounds were tested for their estrogenic activities using an MCF-7 BUS cell proliferation assay, which revealed that compounds 1, 2, and $\mathbf{1 0}$ showed moderate estrogenic activity. To study the mechanism of this estrogenic effect, a docking simulation of compound 1, which showed the best estrogenic activity, was conducted with estrogen receptor (ER) - $\alpha$ and ER- $\beta$, which revealed that it interacts with the key residues of ER- $\alpha$ and ER- $\beta$. In addition, compound 1 had slightly higher affinity for ER- $\beta$ than ER- $\alpha$ in the calculated Gibbs free energy for $1: E R-\alpha$ and $1: E R-\beta$. Thus, the present experimental evidence demonstrated that active compound $\mathbf{1}$ from $A$. tegmentosum could be a promising phytoestrogen for the development of natural estrogen supplements.
\end{abstract}

Keywords: Acer tegmentosum; phenolic compounds; 1,4-benzodioxane scaffold; estrogen; phytoestrogens; molecular docking

\section{Introduction}

Estrogens regulate a variety of physiological functions on organs and tissues such as reproduction, cell growth, and differentiation [1]. In addition, estrogens have crucial role in several pathological functions including cancers, neurodegeneration, metabolic disorders, cardiovascular diseases, and osteoporosis [1-4]. Phytoestrogens, sometimes referred as "dietary estrogens", are plant-derived natural products with the ability to bind to estrogen receptors, which exhibit estrogenic effects in relieving menopausal symptoms such as hot flashes, night sweats, mood changes, depression, and nervous tension [2-4]. Although various phytoestrogens including flavonoids, lignans, 
and anthocyanins have been reported, there are continuing demands to discover more effective and safe phytoestrogens in clinical environment [5-7].

Acer tegmentosum Maxim (Aceraceae) is a deciduous tree widely distributed in Korea. A. tegmentosum has been used in Korean traditional medicine for the treatment of various hepatic disorders, including hepatitis, cirrhosis, and liver cancer [8]. Previous phytochemical investigations on this plant have reported the isolation of various secondary metabolites with useful bioactivities, such as flavonoids, lignans, and phenolic compounds $[9,10]$. Among the isolated compounds, phenethyl glycosides and flavonoids were reported to exhibit hepatoprotective activities [9,10]. In a recent study, fraxin isolated from $A$. tegmentosum as a coumarin glycoside, displayed potent hepatoprotective effects through antioxidant activity and the nuclear factor erythroid-derived 2-related factor 2 (Nrf2)-mediated antioxidant enzyme system [11]. In addition, antioxidant, anti-inflammation, and anti-adipogenic activities have been reported in a biological study on the extract of A. tegmentosum [12,13].

As an endeavor to explore structurally and/or biologically active new constituents from Korean medicinal plants [14-18], a phytochemical investigation was performed on the bark of $A$. tegmentosum, which led to the isolation of one new phenolic compound (1) with a 1,4-benzodioxane scaffold, as well as nine known phenolic compounds (2-10) from the aqueous extracts of the bark. The planar structure of the new compound (1) was elucidated through analysis of $1 \mathrm{D}$ and $2 \mathrm{D}\left\{{ }^{1} \mathrm{H}-{ }^{1} \mathrm{H}\right.$ correlation spectroscopy (COSY), heteronuclear single-quantum correlation spectroscopy (HSQC), and heteronuclear multiple-bond correlation spectroscopy (HMBC)\} NMR data and LC/MS analysis. In addition, the absolute configuration of $\mathbf{1}$ was determined based on quantum chemical ECD calculations. The estrogenic effects of the isolated compounds were assessed by E-screen assays with MCF-7 BUS cells. Moreover, mechanism of the estrogenic effect with estrogen receptor was investigated by using docking analysis. In this paper, the isolation and structural elucidation of compounds 1-10 from the bark of $A$. tegmentosum, along with their estrogenic effects, were described.

\section{Materials and Methods}

\subsection{General Experimental Procedures}

Optical rotations were obtained using a Jasco P-1020 polarimeter (Jasco, Easton, MD, USA). IR spectra were acquired utilizing a Bruker IFS-66/S FT-IR spectrometer (Bruker, Karlsruhe, Germany). Electrospray ionization (ESI) and HR-ESI mass spectra were transcribed using a Waters Micromass Q-TofUltima ESI-TOF mass spectrometer (Waters, New York, NY, USA). Experimental ECD spectra in $\mathrm{MeOH}$ were acquired in a quartz cuvette with a 1-mm optical path length on a JASCO J-1500 spectropolarimeter. (Tokyo, Japan). The ECD spectrum of $\mathrm{MeOH}$ was used as a baseline and subtracted from the experimental spectra. NMR spectra were recorded on a Varian UNITY INOVA $800 \mathrm{NMR}$ spectrometer operating at $800 \mathrm{MHz}\left({ }^{1} \mathrm{H}\right)$ and $200 \mathrm{MHz}\left({ }^{13} \mathrm{C}\right)$, with chemical shifts given in ppm ( $\delta$ ). Preparative high performance liquid chromatography (HPLC) was performed using a Waters 1525 Binary HPLC pump with a Waters 996 Photodiode Array Detector (Waters Corporation, Milford, CT, USA). Semi-preparative HPLC utilized a Shimadzu Prominence HPLC System with SPD-20A/20AV Series Prominence HPLC UV-Vis Detectors (Shimadzu, Tokyo, Japan). LC/MS analysis was performed on an Agilent 1200 Series HPLC system (Agilent Technologies, Santa Clara, CA, USA) using an analytical Kinetex column $(4.6 \times 100 \mathrm{~mm}, 3.5 \mu \mathrm{m})$, followed by a 6130 Series ESI mass spectrometer equipped with a diode array detector. Silica gel 60 (Merck, Darmstadt, Germany; 70-230 mesh and 230-400 mesh) and RP-C18 silica gel (Merck, 40-63 $\mu \mathrm{m}$ ) were used for column chromatography. The packing material for molecular sieve column chromatography was Sephadex LH-20 (Pharmacia, Uppsala, Sweden). Precoated silica gel F254 plates and RP-18 F254s plates (Merck) were used for TLC. Spots were detected on TLC under UV light or by heating after spraying with anisaldehyde-sulfuric acid. 


\subsection{Plant Material}

The bark of A. tegmentosum was obtained from Hongcheon and Jeongseon in the Gangwon province, Korea in June 2013. The identity of the material was confirmed by one of the authors (K. H. Kim). A voucher specimen (MIMH-35) was deposited in the herbarium of the School of Pharmacy, Sungkyunkwan University, Suwon, Korea.

\subsection{Extraction, Fractionation, and Purification Methods}

The bark of $A$. tegmentosum was dried at $60^{\circ} \mathrm{C}$ for $24 \mathrm{~h}$ and then pulverized to afford powdered $A$. tegmentosum bark (200 g). The material was extracted with distilled water $(1 \mathrm{~L})$ at $90{ }^{\circ} \mathrm{C}$ for $10 \mathrm{~h}$ and then filtered. The filtrate was concentrated in vacuo to afford resultant extracts (13.2 g). The resultant extracts were suspended in distilled water $(700 \mathrm{~mL} \times 3)$ and successively solvent-partitioned with hexane, $\mathrm{CH}_{2} \mathrm{Cl}_{2}$, EtOAc, and $n$ - $\mathrm{BuOH}$, affording $62.1 \mathrm{~g}, 32.2 \mathrm{~g}, 22.4 \mathrm{~g}$, and $37.3 \mathrm{~g}$ fractions, respectively. The EtOAc-soluble fraction was loaded onto a Diaion HP-20 column, and fractionated with a gradient solvent system of $20 \%, 40 \%, 60 \%, 80 \%$, and $100 \% \mathrm{MeOH}$ in $\mathrm{H}_{2} \mathrm{O}$ (each $500 \mathrm{~mL}$ ). Based on the results of a TLC analysis, the $80 \%$ and $100 \% \mathrm{MeOH}$ miscible fractions were combined into one fraction. The combined fraction (4.2 g) was separated by RP-C18 silica gel (230-400 mesh) column chromatography, with elution by a gradient solvent system of $\mathrm{MeOH}_{-} \mathrm{H}_{2} \mathrm{O}(1: 1-1: 0, v / v)$ to afford three fractions (A-C). Fraction B (3.3 g) was subjected to silica gel (230-400 mesh) column chromatography and separated with a gradient solvent system of EtOAc-MeOH $(30: 1-1: 1, v / v)$ to provide three fractions (BA-BC). Three fractions (BA1-3) were acquired from fraction BA (511 mg) by Sephadex LH-20 column chromatography eluted with 100\% MeOH. Fraction BA1 (147 mg) was further fractionated by silica gel (70-230 mesh) column chromatography with a gradient solvent system of $\mathrm{CH}_{2} \mathrm{Cl}_{2}-\mathrm{MeOH}$ (50:1 to $1: 1, v / v)$ to provide six subfractions (BA11-16). Subfraction BA12 (20 mg) was purified by semipreparative reversed-phase HPLC (Phenomenex Luna Phenyl-hexyl, $250 \times 10.0 \mathrm{~mm}, 5 \mu \mathrm{m}$ ) eluted with $37 \% \mathrm{MeOH} / \mathrm{H}_{2} \mathrm{O}$ (flow rate: $2 \mathrm{~mL} / \mathrm{min}$ ) to afford compound $2\left(3.0 \mathrm{mg}, t_{\mathrm{R}}=50.0 \mathrm{~min}\right.$ ). Three subfractions (BA21-23) were obtained from fraction BA2 $(187 \mathrm{mg})$ by silica gel (70-230 mesh) column chromatography with a gradient solvent system of $\mathrm{CH}_{2} \mathrm{Cl}_{2}-\mathrm{MeOH}(30: 1$ to 0:1, v/v). Subfraction BA22 (62 mg) was isolated by semipreparative reversed-phase HPLC (Phenomenex Luna Phenyl-hexyl, $250 \times 10.0 \mathrm{~mm}, 5 \mu \mathrm{m})$ using $37 \% \mathrm{MeOH} / \mathrm{H}_{2} \mathrm{O}$ (flow rate: $2 \mathrm{~mL} / \mathrm{min}$ ) to provide compounds $4(7.6 \mathrm{mg}$, $\left.t_{\mathrm{R}}=58.0 \mathrm{~min}\right), 7\left(4.6 \mathrm{mg}, t_{\mathrm{R}}=55.0 \mathrm{~min}\right), \mathbf{9}\left(7.3 \mathrm{mg}, t_{\mathrm{R}}=26.0 \mathrm{~min}\right)$, and $10\left(1.0 \mathrm{mg}, t_{\mathrm{R}}=20.0 \mathrm{~min}\right)$. Fraction BB (564 mg) was loaded onto a Sephadex LH-20 column and fractionated using elution with $100 \% \mathrm{MeOH}$ to give five fractions (BB1-BB5). Four subfractions (BB41-44) were gained from fraction BB4 (135 mg) by preparative reversed-phase HPLC (Luna C-18 column, $250 \mathrm{~mm} \times 21.2 \mathrm{~mm}$ i.d., $5 \mu \mathrm{m}$ ) with a gradient solvent system of $\mathrm{CH}_{3} \mathrm{CN}-\mathrm{H}_{2} \mathrm{O}(1: 9-1: 0, v / v$, flow rate: $5 \mathrm{~mL} / \mathrm{min})$. Subfraction BB41 (15 mg) was separated by semipreparative reversed-phase HPLC (Phenomenex Luna Phenyl-hexyl, $250 \times 10.0 \mathrm{~mm}, 5 \mu \mathrm{m}$ ) eluted with $30 \% \mathrm{MeOH} / \mathrm{H}_{2} \mathrm{O}$ (flow rate: $2 \mathrm{~mL} / \mathrm{min}$ ) to provide compound 8 $\left(8.1 \mathrm{mg}, t_{\mathrm{R}}=33.0 \mathrm{~min}\right)$. Subfraction BB44 $(12 \mathrm{mg})$ was purified by semipreparative reversed-phase HPLC (Phenomenex Luna Phenyl-hexyl, $250 \times 10.0 \mathrm{~mm}, 5 \mu \mathrm{m}$ ) eluted with $36 \% \mathrm{MeOH} / \mathrm{H}_{2} \mathrm{O}$ (flow rate: $2 \mathrm{~mL} / \mathrm{min})$ to afford compound $6\left(3.9 \mathrm{mg}, t_{\mathrm{R}}=50.0 \mathrm{~min}\right)$. Fraction BB5 $(84 \mathrm{mg})$ was separated using semipreparative reversed-phase HPLC (Phenomenex Luna Phenyl-hexyl, $250 \times 10.0 \mathrm{~mm}, 5 \mu \mathrm{m}$ ) eluted with $32 \% \mathrm{MeOH} / \mathrm{H}_{2} \mathrm{O}$ (flow rate: $2 \mathrm{~mL} / \mathrm{min}$ ) to provide compound $5\left(4.0 \mathrm{mg}, t_{\mathrm{R}}=42.0 \mathrm{~min}\right.$ ). Fraction BC (928 mg) was passed through Sephadex LH-20 column chromatography using 100\% $\mathrm{MeOH}$ to give eight subfractions (BC1-8). Compounds $1\left(7.7 \mathrm{mg}, t_{\mathrm{R}}=45.0 \mathrm{~min}\right)$ and $3\left(3.8 \mathrm{mg}\right.$, $t_{\mathrm{R}}$ $=20.0 \mathrm{~min})$ were purified from subfraction $\mathrm{BC} 5(43 \mathrm{mg})$ by semipreparative reversed-phase HPLC (Phenomenex Luna Phenyl-hexyl, $250 \times 10.0 \mathrm{~mm}, 5 \mu \mathrm{m}$ ) eluted with $38 \% \mathrm{MeOH} / \mathrm{H}_{2} \mathrm{O}$ (flow rate: $2 \mathrm{~mL} / \mathrm{min})$.

Isoamericanoic acid B (1): amorphous powder; $[\alpha]_{D}^{25}+10.6$ (c $\left.0.02, \mathrm{MeOH}\right) ; \mathrm{IR}(\mathrm{KBr}) v_{\max } 3454$, 1781, 1439, 1206, $1054 \mathrm{~cm}^{-1}$; UV (MeOH) $\lambda_{\max }(\log \varepsilon) 225$ (3.90), 257 (3.75), 289 (3.41) nm; ECD (MeOH) $\lambda(\triangle \varepsilon) 206$ (1.23), $220(-7.20), 238(0.62) \mathrm{nm} ;{ }^{1} \mathrm{H}(800 \mathrm{MHz})$ and ${ }^{13} \mathrm{C}$ NMR (200 MHz) data, see Table 1; HR-ESIMS (negative ion-mode) $m / z 377.0873[\mathrm{M}-\mathrm{H}]^{-}$(calcd for $\mathrm{C}_{18} \mathrm{H}_{18} \mathrm{O}_{9}, 377.0873$ ). 
Table 1. ${ }^{1} \mathrm{H}(800 \mathrm{MHz})$ and ${ }^{13} \mathrm{C}(200 \mathrm{MHz})$ nuclear magnetic resonance (NMR) data of $\mathbf{1}$ in $\mathrm{CD}_{3} \mathrm{OD}^{\mathrm{a}}$.

\begin{tabular}{ccc}
\hline \multirow{2}{*}{ Position } & \multicolumn{2}{c}{$\mathbf{1}$} \\
\cline { 2 - 3 } & $\delta_{\mathbf{C}}$ & $\delta_{\mathbf{H}}(\boldsymbol{J}$ in Hz$)$ \\
\hline 1 & $128.3 \mathrm{~s}$ & \\
3,6 & $106.1 \mathrm{~d}$ & $6.64 \mathrm{~s}$ \\
4 & $149.7 \mathrm{~s}$ & \\
7 & $137.6 \mathrm{~s}$ & \\
8 & $78.2 \mathrm{~d}$ & $4.75 \mathrm{~d}(8.0)$ \\
9 & $60.4 \mathrm{~d}$ & $4.07 \mathrm{~m}$ \\
& $62.3 \mathrm{t}$ & $3.47 \mathrm{dd}(12.0,6.0)$ \\
$1^{\prime}$ & $125.5 \mathrm{~s}$ & $3.56 \mathrm{~d}(12.0)$ \\
$2^{\prime}$ & $111.3 \mathrm{~d}$ & $7.04 \mathrm{br} \mathrm{s}$ \\
$3^{\prime}$ & $145.7 \mathrm{~s}$ & \\
$4^{\prime}$ & $137.5 \mathrm{~s}$ & \\
$5^{\prime}$ & $147.3 \mathrm{~s}$ & \\
$6^{\prime}$ & $111.4 \mathrm{~d}$ & $7.04 \mathrm{br} \mathrm{s}$ \\
$3,5^{-O M e}$ & $57.0 \mathrm{q}$ & $3.77 \mathrm{~s}$ \\
$1^{\prime}-\mathrm{COOH}$ & $170.9 \mathrm{~s}$ & \\
\hline a & & \\
\hline
\end{tabular}

${ }^{\text {a }}$ Coupling constants (in parentheses) are in $\mathrm{Hz}$.

\subsection{Computational Analysis}

To obtain the conformational differences between $\mathbf{1 a}(7 R, 8 R)$ and $\mathbf{1 b}(7 S, 8 S)$, computational discrete fourier transform (DFT) calculations were carried out. The first structural energy minimization of $\mathbf{1 a}$ and $\mathbf{1 b}$ were performed by utilizing the Avogadro 1.2.0 software (Pittsburgh, PA, USA) with the UFF force field. Then, the ground-state geometries of $\mathbf{1 a}$ and $\mathbf{1} \mathbf{b}$ were established using Tmolex 4.3.1 software (Leverkusen, Germany) with the DFT settings (B3-LYP functional/M3 grid size), geometry optimization options (energy $10^{-6}$ hartree, gradient norm $|\mathrm{dE} / \mathrm{dxyz}|=10^{-3}$ hartree/bohr), and the basis set def-SV(P) for all atoms. The calculated ECD spectra of the optimized structures of $\mathbf{1 a}$ and $\mathbf{1 b}$ were acquired using the B3LYP/DFT functional settings, with the basis set def2-TZVPP, for all atoms. The obtained CD spectra were simulated by overlying each transition, where $\sigma$ is the width of the band at $1 /$ e height. $\Delta E_{i}$ and $R_{i}$ are the excitation energies and rotatory strengths for transition $i$, respectively. In the present study, the value of $\sigma$ was $0.10 \mathrm{eV}$.

$$
\Delta \epsilon(E)=\frac{1}{2.297 \times 10^{-39}} \frac{1}{\sqrt{2 \pi \sigma}} \sum_{A}^{i} \Delta E_{i} R_{i} e^{\left[-\left(E-\Delta E_{i}\right)^{2} /(2 \sigma)^{2}\right]}
$$

\subsection{Cell Culture and WST-1 Cell Cytotoxicity Assays}

Estrogen-sensitive MCF-7 BUS human breast cancer cells were kindly provided by Dr. Soto (Tufts University, Boston, MA, USA). MCF-7 BUS cells were maintained in red-dulbecco's modified eagle medium (DMEM) supplemented with $5 \%$ fetal bovin serum (FBS), penicillin (100 units $/ \mathrm{mL}$ ), and streptomycin $(100 \mu \mathrm{g} / \mathrm{mL})$ in a humidified incubator at $37^{\circ} \mathrm{C}$ and $5 \% \mathrm{CO}_{2} / 95 \%$ air. The cellular cytotoxicity of compounds was tested by WST- 1 assays. Briefly, cells were seeded at 5000 cells $/ 100 \mu 1$ medium/well into 96-well plates. After $24 \mathrm{~h}$ of incubation, the medium was replaced with experimental charcoal dextran-treated medium (10\% CD-FBS supplemented with phenol red-free DMEM) containing test compounds at various concentrations. Cells were incubated with test compounds for $48 \mathrm{~h}$, after which WST-1 reagent was added to each well (final dilution, 1:10). Cells were then incubated for $1 \mathrm{~h}$ at $37^{\circ} \mathrm{C}$. Cell viability was quantified by measuring the absorbance at $440 \mathrm{~nm}$ using a VERSAmax microplate reader (Molecular Devices, Sunnyvale, CA, USA). 


\subsection{E-Screen Assay}

The estrogenic effects of compounds were assessed by E-screen assays with MCF-7 BUS cells, as previously described [19]. Briefly, the cells were harvested and suspended in 5\% FBS DMEM before being seeded into 48 -well plates at $5 \times 10^{3}$ cells/well. After $48 \mathrm{~h}$ of incubation, the medium was replaced with charcoal dextran-treated medium containing test compounds at various concentrations. After a further $144 \mathrm{~h}$ of incubation, cellular proliferation was measured using the sulforhodamine $\mathrm{B}$ staining method. Cellular proliferation data are represented as relative proliferative effects (RPEs) of MCF-7 BUS cells, which were calculated as follows: $\operatorname{RPE}=\{(\mathrm{S}-1) /(\mathrm{E}-1)\} \times 100$, where $S=$ proliferation of experimental samples and $E=$ proliferation of positive control $\left(10^{-9} \mathrm{M} \mathrm{E}_{2}\right)$.

\subsection{RT-PCR Assay}

MCF-7 BUS cells were seeded into a six-well plate and incubated for $24 \mathrm{~h}$ at $37^{\circ} \mathrm{C}$. The medium was replaced with charcoal dextran-treated medium containing $E_{2}\left(10^{-9} \mathrm{M}\right)$ or compound $\mathbf{1}(80 \mu \mathrm{M})$. After $48 \mathrm{~h}$ of incubation, total RNA was extracted using RNAiso Plus reagent (Takara, Shiga, Japan). Complementary DNA (cDNA) was synthesized by using a RT Premix kit (Bioneer, Daejeon, Korea) with $0.5 \mu \mathrm{g} / \mathrm{mL}$ random primers. The PCR was performed in PCR thermocycler (MJ Ressearch; Marshall Scientific, Hampton, NH, USA). The PCR amplification for pS2 and $\alpha$-actin was 29 cycles at $94{ }^{\circ} \mathrm{C}$ for $30 \mathrm{~s}, 55^{\circ} \mathrm{C}$ for $1 \mathrm{~min}, 72{ }^{\circ} \mathrm{C}$ for $2 \mathrm{~min}$. The PCR product run in $1.5 \%$ agarose gel electrophoresis in TBE buffer with ethidium bromide. The PCR products were detected and analyzed with gel documentation and analysis system (UVP).

(1) $\alpha$-actin Forward: $5^{\prime}$-GGAGCAATGATCTTGATCTT- $3^{\prime}$

(2) $\alpha$-actin Reverse: $5^{\prime}$-CCTTCTGGGCATGGAGTCCT- $3^{\prime}$

(3) pS2 Forward: $5^{\prime}$-CATGGAGAACAAGGTGATCTG-3'

(4) pS2 Reverse: 5'-CAGAAGCGTGTCTGAGGTGTC-3'

\subsection{Molecular Docking}

Docking modeling was carried out using the molecular modeling package Sybyl-X 2.1.1 (Tripos Inc, St Louis, MO, USA). Structure of $\mathbf{1}$ was sketched using sketch module, and energy minimization was conducted under the Tripos force field using the conjugated gradient method, which was set to converge to the maximum derivatives of $0.001 \mathrm{kcal} \mathrm{mol}^{-1} . \AA^{-1}$. To prepare the receptor protein, the coordinate files of estrogen receptor (ER)- $\alpha$ (PDB id: 1A52) [20] and ER- $\beta$ (PDB id: 5TOA) [21] were retrieved from the Protein Data Bank (PDB). All water molecules and duplicated chains were removed, and the bound $17 \beta$-estradiol was extracted. The extracted $17 \beta$-estradiol was also prepared for re-docking by adding hydrogen atoms, correcting atom types and wrong valences, and assigning Gasteiger-Hückel charge on all atoms. Each protomol of ER was generated based on the native ligand, $17 \beta$-estradiol. For docking process, all parameters were set to default, and 50 conformers per ligand were generated. The binding affinities of each ligand docking pose were calculated by Surflex-Dock scores and the consensus scoring function. The high-ranked poses with good Surflex-Dock scores (total score, Cscore) were selected, and the representative docking model was selected by visual inspection by considering the important binding interactions of compound $\mathbf{1}$ with the receptor.

\subsection{Statistical Analysis}

GraphPad Prism software (GraphPad Software, La Jolla, CA, USA) and Excel 2016 (Microsoft, Redmond, WA, USA) were used for data analysis. Each in vitro assay was performed at least in triplicate, and the data from each assay were expressed as means \pm standard deviations (SDs). Statistical significance was assessed by a one-way analysis of variance (ANOVA) followed by Duncan's post hoc test. Differences with $p<0.05$ were considered statistically significant. 


\section{Results and Discussion}

\subsection{Phytochemical Investigation and Isolation of Compounds}

Dried and pulverized A. tegmentosum bark was extracted with distilled water at $90{ }^{\circ} \mathrm{C}$ for $10 \mathrm{~h}$ and then filtered. The filtrate was evaporated under reduced pressure with a rotavapor to obtain a crude aqueous extract. The resultant extracts were suspended in distilled water and successively solvent-partitioned with hexane, $\mathrm{CH}_{2} \mathrm{Cl}_{2}$, EtOAc, and $n-\mathrm{BuOH}$, affording four main fractions. According to an LC/MS analysis equipped with in-house UV spectra library, the EtOAc-soluble fraction was determined to contain promising compounds, which led us to investigate the EtOAc-soluble fraction to identify structurally and/or biologically active new constituents. Extensive, repeated column chromatography and semi-preparative HPLC purification of the EtOAc-soluble fraction afforded the isolation of one new phenolic compound (1) with a 1,4-benzodioxane scaffold, together with nine known phenolic compounds (2-10) (Figure 1).
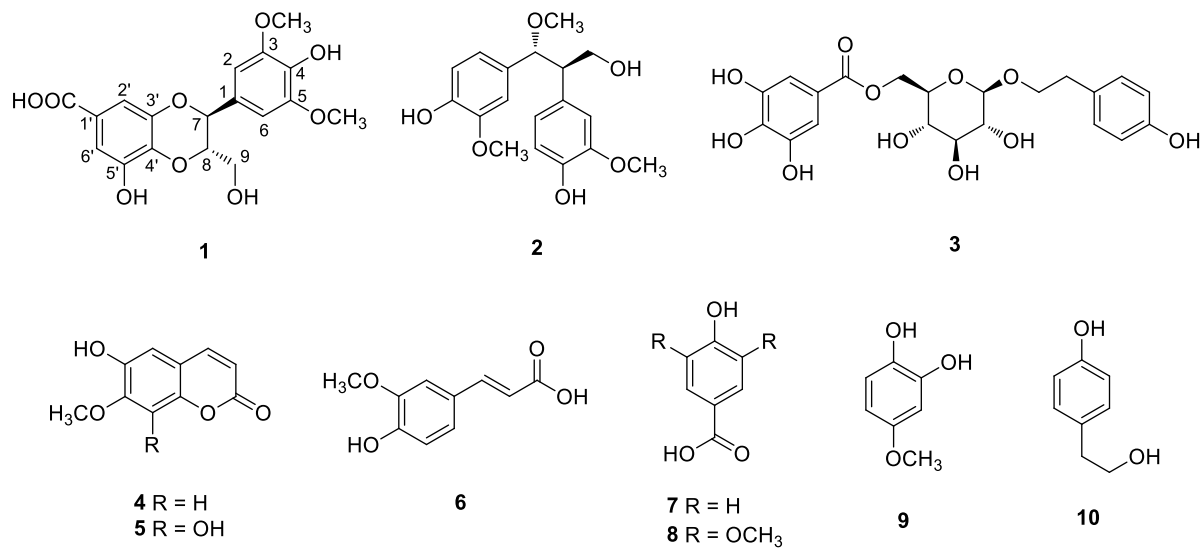

Figure 1. Chemical structures of compounds 1-10.

\subsection{Structural Identification of the Isolated Compounds}

Compound 1 was purified as an amorphous powder with a positive specific rotation value $\left([\alpha]_{D}^{25}\right.$ +10.6 , in $\mathrm{MeOH}$ ), and its molecular formula was determined to be $\mathrm{C}_{18} \mathrm{H}_{18} \mathrm{O}_{9}$ from the $[\mathrm{M}-\mathrm{H}]^{-}$peak at $m / z 377.0873$ (calcd for $\mathrm{C}_{18} \mathrm{H}_{18} \mathrm{O}_{9}, 377.0873$ ) in the HR-ESIMS data. The ${ }^{1} \mathrm{H}$ NMR spectrum of compound 1 (Table 1 ) displayed signals for aromatic protons at $\delta_{\mathrm{H}} 6.64(2 \mathrm{H}, \mathrm{s})$, and $7.04(2 \mathrm{H}$, br s); two oxygenated methines at $\delta_{\mathrm{H}} 4.07(1 \mathrm{H}, \mathrm{m})$ and $4.75(1 \mathrm{H}, \mathrm{d}, J=8.0 \mathrm{~Hz})$; one oxygenated methylene at $\delta_{\mathrm{H}} 3.47(1 \mathrm{H}, \mathrm{dd}, J=12.0,6.0 \mathrm{~Hz})$ and $3.56(1 \mathrm{H}, \mathrm{d}, J=12.0 \mathrm{~Hz})$; and two methoxy groups at $\delta_{\mathrm{H}}$ $3.77(6 \mathrm{H}, \mathrm{s})$. The ${ }^{13} \mathrm{C}$ NMR data of $\mathbf{1}$ (Table 1 ) showed a total of 18 carbon resonances attributable to 12 aromatic $\mathrm{sp}^{2}$ carbons at $\delta_{\mathrm{C}} 106.1(\times 2), 111.3,111.4,125.5,128.3,137.5,137.6,145.7,147.3$, and $149.7(\times 2)$; three oxygenated carbons at $\delta_{\mathrm{C}} 62.3,78.2$, and 80.4 ; two methoxy carbons at $\delta_{\mathrm{C}} 57.0(\times 2)$; and one ester carbon at $\delta_{\mathrm{C}} 170.9$. Thorough analysis of the ${ }^{1} \mathrm{H}$ and ${ }^{13} \mathrm{C}$ NMR data of 1 revealed that the NMR data were similar to those of 3-O-methyl isoamericanoic acid A, identified from the bark of Picea jezoensis, with apparent differences being that the signals for aromatic protons were absent in 3-O-methyl isoamericanoic acid $\mathrm{A}$ and the signals for an additional methoxy group $\left[\delta_{\mathrm{H}} 3.77(\mathrm{~s}) ; \delta_{\mathrm{C}}\right.$ 57.0] were present in compound 1 [22]. The complete structure of 1 based on the inspection of the above ${ }^{1} \mathrm{H}$ and ${ }^{13} \mathrm{C}$ NMR data was further confirmed by the interpretation of 2D NMR experiments $\left({ }^{1} \mathrm{H}^{-1} \mathrm{H}\right.$ COSY, HSQC, and HMBC) (Figure 2). The position of the additional methoxy group was determined to be $\mathrm{C}-5$ based on an HMBC correlation from the methoxy protons to C-5, as well as the presence of symmetric protons and carbons $\left[\delta_{\mathrm{H}} 6.64(\mathrm{~s}) ; \delta_{\mathrm{C}} 106.1\right]$. The down-field shifted quaternary carbon at $\delta_{\mathrm{C}} 147.3\left(\mathrm{C}-5^{\prime}\right)$ and HMBC correlations from $\mathrm{H}-6^{\prime}$ to $\mathrm{C}-1^{\prime}, \mathrm{C}-2^{\prime}, \mathrm{C}-4^{\prime}$, and $\mathrm{C}-5^{\prime}$ suggested that a hydroxyl group was substituted at $\mathrm{C}-5^{\prime}$. 


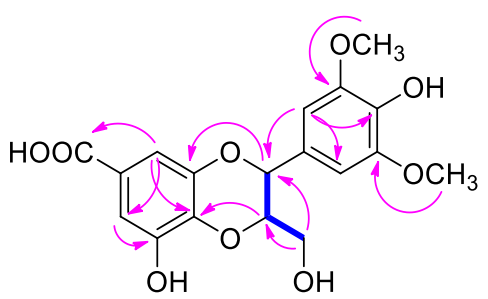

Figure 2. Key ${ }^{1} \mathrm{H}^{-1} \mathrm{H}$ COSY (blue lines) and key $\mathrm{HMBC}$ (heteronuclear multiple-bond correlation spectroscopy) (pink arrows) for compound $\mathbf{1}$.

The relative stereochemistry of $\mathbf{1}$ was deduced by utilizing the $J$-based configuration analysis (JBCA) method. The coupling constant of $J_{\mathrm{H} 7, \mathrm{H} 8}=8.0 \mathrm{~Hz}$ in the ${ }^{1} \mathrm{H}$ NMR data revealed that the relative configuration between H-7 and H-8 was trans [23,24]. The absolute configuration of $\mathbf{1}$ was determined by comparing the experimental ECD spectrum of $\mathbf{1}$ with calculated ECD data of $\mathbf{1 a}(7 S, 8 S)$ and $\mathbf{1} \mathbf{b}$ $(7 R, 8 R)$. The experimental ECD spectrum of 1 exhibited a negative Cotton effect at around $220 \mathrm{~nm}$, matching well with the calculated ECD data for 1a (Figure 3). Thus, the absolute configuration of C-7 and C-8 in 1 was assigned as 7S, 8S, respectively. Accordingly, the chemical structure of $\mathbf{1}$ was finally determined, as shown in Figure 1, and named as isoamericanoic acid B. Recently, a pair of enantiomeric methyl esters [ $(7 S, 8 S)$ - and $(7 R, 8 R)$-pithecellobiumin $\mathrm{A}]$ of compound 1 was isolated from the twigs and leaves of Pithecellobium clypearia [25] and exhibited anti-A $\beta$ aggregation activity.

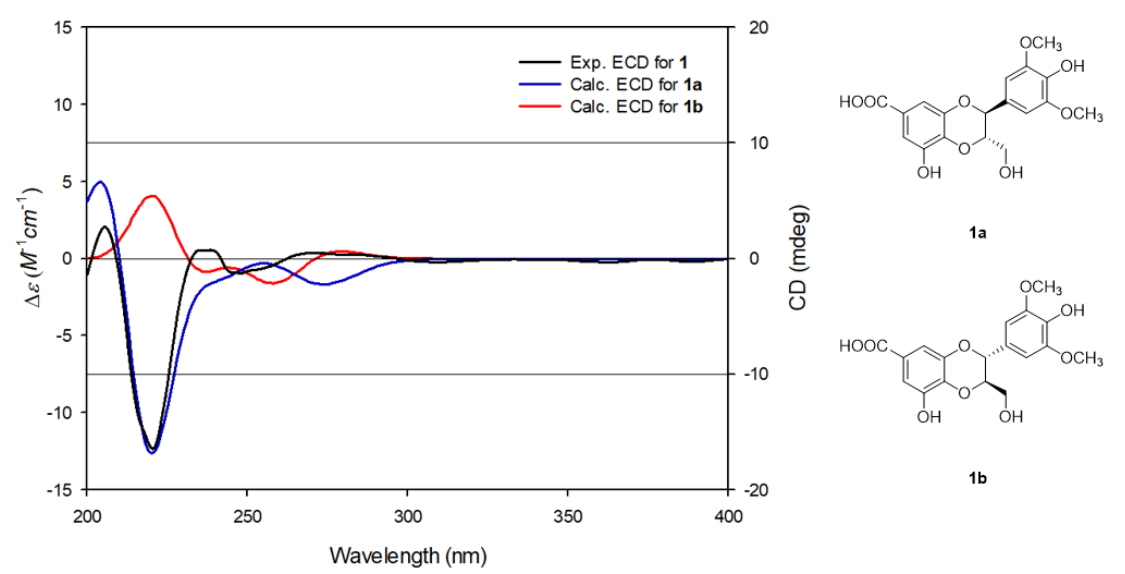

Figure 3. Experimental and calculated ECD (electronic circular dichroism) spectra of compounds 1, 1a, and $\mathbf{1 b}$.

The known compounds were identified as 4,4'-((1R,2R)-3-hydroxy-1-methoxypropane-1,2-diyl)bis (2-methoxyphenol) (2) [26], 6-O-galloylsalidroside (3) [27], isoscopoletin (4) [28], 6,8-dihydroxy-7-meth oxy-2H-1-benzopyran-2-one (5) [29], trans-ferulic acid (6) [30], 4-hydroxybenzoic acid (7) [31], syringic acid (8) [32], 4-methoxycatechol (9) [33], and 4-hydroxyphenylethanol (10) [34] by comparing the spectroscopic data obtained in this study with values reported in previous studies. To the best of our knowledge, compounds 2, 4, 5, and 9 were structurally identified from the bark of A. tegmentosum for the first time in this study.

\subsection{Estrogenicity of Compounds Isolated from A. Tegmentosum}

During the menopausal transition, many women suffer menopausal symptoms, such as hot flashes, night sweats, mood changes, depression and nervous tension, due to lower estrogen levels $[35,36]$. These symptoms can be ameliorated by hormone replacement therapy (HRT). However, current HRT appears to be associated with increased risks of developing breast and ovarian cancers in healthy women and have limitations to use for patients with breast cancer [37]. To overcome the shortcomings of HRT, new and safe phytoestrogens, which are plant-derived compounds 
resembling estrogen, have emerged as an alternative to conventional HRT to alleviate the symptoms of menopause [38]. Phytoestrogens are potential HRT agents that can act as both estrogen and anti-estrogen agents depending on the circulating endogenous estrogen levels [36]. Phytoestrogens mainly belong to a large group of natural phenolic compounds and they are known to exert their effects primarily through binding to estrogen receptors (ER), ER- $\alpha$, and ER- $\beta$. ER- $\alpha$ is present mainly in female reproductive tissues (uterus and ovary), breast, kidney, bone, lung, and cardiovascular system, while ER- $\beta$ is found in all over the body regardless of sex [1,2,5]. Among phytoestrogens, isoflavones are considered to be the most active natural products with respect to estrogenic effects.

First, the cytotoxicity of the compounds isolated from A. tegmentosum were tested using a WST-1 assay after $48 \mathrm{~h}$ of treatment (Figure $4 \mathrm{~A}$ ). Compounds that were not cytotoxic (at 40, 80, and $160 \mu \mathrm{M}$ ) were selected for assessment of their estrogenic activity. Compounds were dispersed in CD-FBS medium and incubated with MCF-7 BUS cells for $144 \mathrm{~h}$. The estrogenicity of the compounds was calculated as the cell proliferation relative to that seen in the presence of $10^{-9} \mathrm{M} 17 \beta$-estradiol and is represented as the relative proliferative effect (RPE). Among the isolated compounds, compounds 1, 2, and 10 showed estrogenic activities (Figure $4 \mathrm{~B}$ ). At $80 \mu \mathrm{M}$, each compound showed 22.1 (1), 12.3 (2), and 6.9 (10) RPE values, which is similar to the pattern observed with 163,69 and $17 \mathrm{pM}$ of $17 \beta$-estradiol (Figure $4 \mathrm{C}$ ). In addition, $p S 2$ gene expression was measured after treatment of compound 1 , which showed the highest estrogen activity at $80 \mu \mathrm{M}$. The $p S 2$ gene is regulated by estrogen at the transcriptional level and considered ideal marker to measure the estrogen activity [39]. Compound 1 induced pS2 gene expression (Figure 4D), suggesting that compound $\mathbf{1}$ can be a phytoestrogen with moderate estrogenic activity.

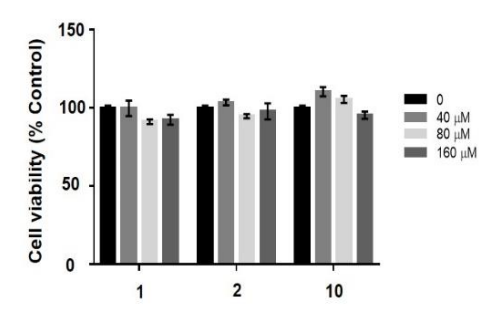

(A)

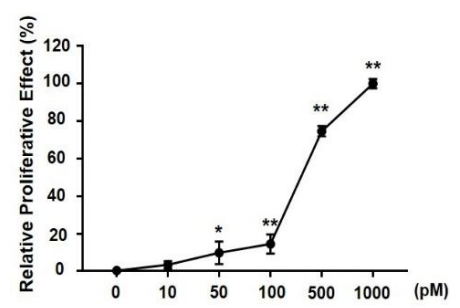

(C)

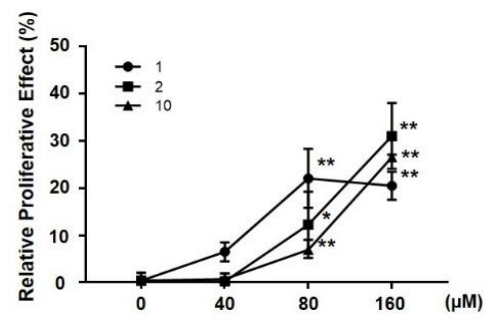

(B)
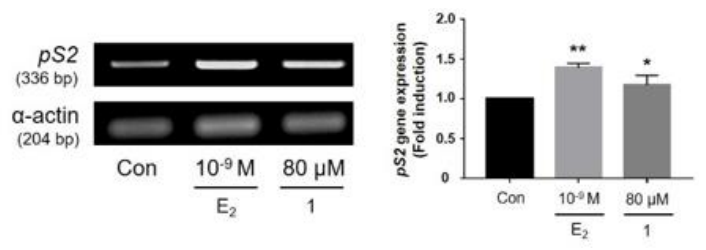

(D)

Figure 4. Cytotoxicity and estrogenic effects of compounds 1, 2, and 10, isolated from Acer tegmentosum, on MCF-7 BUS cells. (A) The effects of the compounds on MCF-7 BUS cell viability were tested by WST-1 assays. Cells were treated with each compound at 20 to $160 \mu \mathrm{M}$ for $48 \mathrm{~h}$, and cell viability was quantified with absorbance at $440 \mathrm{~nm}$ using a microplate reader. Estrogenic effects of (B) compounds (40 to $160 \mu \mathrm{M}$ ) and $(\mathrm{C}) 17 \beta$-estradiol $\left(\mathrm{E}_{2} ; 10-1000 \mathrm{pM}\right.$ ) were measured by E-screen assays. Cells were treated with the indicated concentrations of the compounds for $144 \mathrm{~h}$, then sulforhodamine B (SRB) assays were conducted to measure cell proliferation. Cell proliferation relative to that in the presence of $\mathrm{E}_{2}\left(10^{-9} \mathrm{M} ; 1000 \mathrm{pM}, 100 \%\right)$ was represented as the relative proliferative effect and expressed as mean \pm SD of three separate experiments for each group. (D) Effects of compound 1 on pS2 mRNA expression. Cells were treated with compound 1 for $48 \mathrm{~h}$, then total mRNA was extracted using RNAiso Plus reagent. pS2 mRNA levels were measured by RT-PCR and normalized using $\alpha$-actin mRNA as an internal standard. Symbols $\left({ }^{*},{ }^{* *}\right)$ represent statistical differences from the vehicle control (Con, $0.1 \%$ DMSO): ${ }^{*} p<0.05,{ }^{* *} p<0.01$. 


\subsection{Molecular Docking of Compound 1 into ER- $\alpha$ and ER- $\beta$}

In the E-screen assay results, compound 1 showed the best estrogenic effect in MCF-7 BUS cells among the isolates in this study. Additionally, compound $\mathbf{1}$ has a similar shape to genistein, a well-known natural product ER agonist, with 73.4\% similarity (calculated by the Tanimoto coefficient using the MACCS fingerprint in KNIME 3.6.0 (KNIME AG, Zurich, Switzerland)). To examine the potential binding pose of $\mathbf{1}$ in the active site of ER, a docking analysis of $\mathbf{1}$ using $X$-ray structures of ER- $\alpha$ (PDB id: 1A52) [20] and ER- $\beta$ (PDB id: 5TOA) [21] in complex with 17 $\beta$-estradiol was carried out. As illustrated in Figure 5, compound 1 fit into the ligand-binding pocket of ER and overlaid well atop the $X$-ray pose of $17 \beta$-estradiol. The key interactions between most ER agonists and ER are: (1) hydrogen bonds (H-bonds) with polar residues where two hydroxyl groups in the A and D ring of $17 \beta$-estradiol are anchored by forming H-bonds, and (2) hydrophobic interactions with the amino acid residues in the steroid ring binding pocket. For compound 1, the carboxyl substituent attached to benzodioxane group formed H-bonds with Arg394 (ER- $\alpha$ ) and Arg346 (ER- $\beta$ ), and the phenolic $\mathrm{OH}$ and the methoxy oxygen atom on 2,6-dimethoxyphenol ring were H-bonded to His524 (ER- $\alpha$ ) and His475 (ER- $\beta$ ). In addition, the benzene ring of the benzodioxane group interacted with Phe 404 (ER- $\alpha)$ and Phe356 (ER- $\beta$ ) by a $\pi-\pi$ stacking interaction inside the hydrophobic pocket. The same interactions were also revealed in the X-ray structures, in which the aromatic A ring of $17 \beta$-estradiol formed a $\pi-\pi$ stacking interaction with Phe404 (ER- $\alpha$ ) and Phe356 (ER- $\beta)$. These docking results suggest the capability of compound 1 to bind to the ligand-binding pocket of both ER- $\alpha$ and ER- $\beta$ and act as a phytoestrogen. The binding affinity of $\mathbf{1}$ was also estimated in comparison with $17 \beta$-estradiol using the Surflex-Dock score $\left(-\log K_{d}\right)$. The scores for $17 \beta$-estradiol were obtained by re-docking of the crystallographic binding pose extracted from ER- $\alpha$ and ER- $\beta$, respectively. (Figure S7 in Supplementary Materials) The calculated Gibbs free energy for 1:ER- $\alpha, 1$ :ER- $\beta, 17 \beta$-estradiol:ER- $\alpha$, and the $17 \beta$-estradiol:ER- $\beta$ complex are $-2.36,-2.69,-7.21$, and $-5.63 \mathrm{kcal} / \mathrm{mol}$, respectively (Table 2 ). The results suggest that the 1:ER complex is less stable than $17 \beta$-estradiol:ER in the equilibrium, which is consistent with the estrogenic activity difference for $\mathbf{1}$ and $17 \beta$-estradiol. The results from estimated binding affinity indicated that compound 1 exhibits estrogenic activity and slightly higher binding affinity for ER- $\beta$ than for ER- $\alpha$. Activation of ER- $\beta$ is known to lead inhibition of cell proliferation, tumor suppression, and protection of atherosclerosis $[40,41]$. Phytoestrogens tend to have both estrogenic and anti-estrogenic effects depending on the circulating estrogen levels when they have higher binding affinity for ER- $\beta$ than for ER- $\alpha$ [42]. After menopause, estrogen levels start to decline, and menopause symptoms are often troublesome to women [35,43]. Thus, these results suggest that compound $\mathbf{1}$ may be useful as a promising phytoestrogen for the development of natural estrogen supplements.

Table 2. Calculated Gibbs free binding energy for 1:ER versus the $17 \beta$-estradiol:ER complex.

\begin{tabular}{|c|c|c|c|c|c|c|c|}
\hline \multicolumn{4}{|c|}{ ER- $\alpha$ (pdb id: 1A52) } & \multicolumn{4}{|c|}{ ER- $\beta$ (pdb id: 5 TOA) } \\
\hline Ligand & $\begin{array}{c}\text { Surflex-Dock } \\
\text { Score }\left(-\log K_{d}\right)\end{array}$ & $K_{d}$ & $\begin{array}{c}\text { Gibbs Free } \\
\text { Energy } \\
\left(\Delta G_{b i n d}\right)\end{array}$ & Ligand & $\begin{array}{c}\text { Surflex-Dock } \\
\text { Score }\left(-\log K_{d}\right)\end{array}$ & $K_{d}$ & $\begin{array}{c}\text { Gibbs Free } \\
\text { Energy }^{*} \\
\left(\Delta G_{b i n d}\right)\end{array}$ \\
\hline 1 & 1.7299 & $1.86 \times 10^{-2}$ & $-2.36 \mathrm{kcal} / \mathrm{mol}$ & 1 & 1.9724 & $1.06 \times 10^{-2}$ & $-2.69 \mathrm{kcal} / \mathrm{mol}$ \\
\hline $17 \beta$-estradiol & 5.2866 & $5.15 \times 10^{-6}$ & $-7.21 \mathrm{kcal} / \mathrm{mol}$ & $17 \beta$-estradiol & 4.1318 & $7.38 \times 10^{-5}$ & $-5.63 \mathrm{kcal} / \mathrm{mol}$ \\
\hline
\end{tabular}


(A)

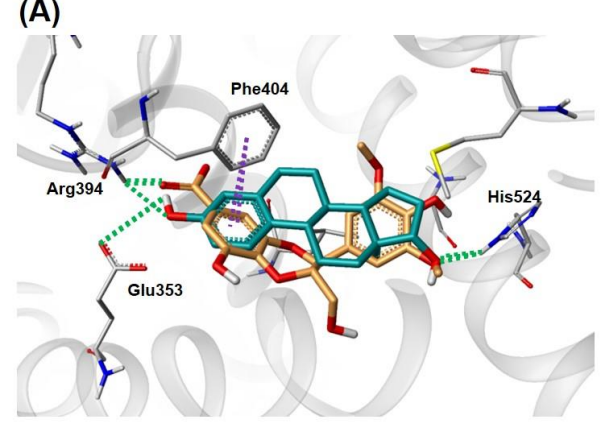

(C)

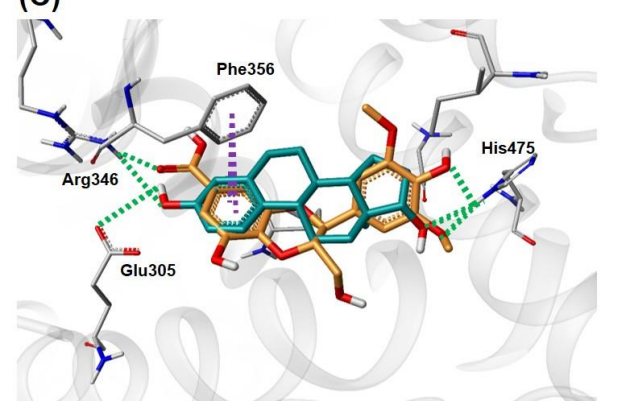

(B)

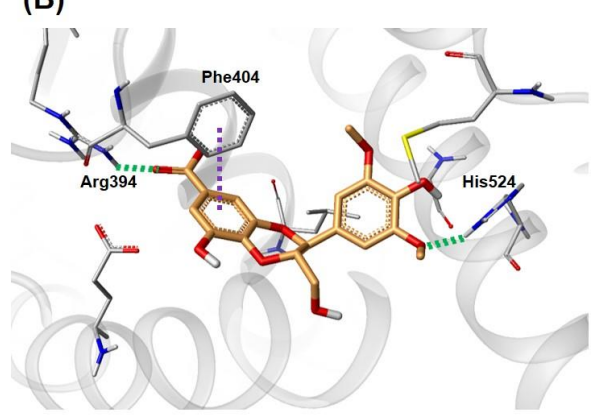

(D)

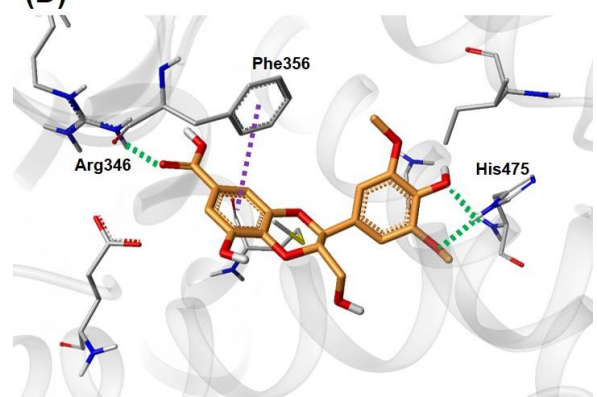

Figure 5. Proposed binding pose of compound 1 in the active site of ER- $\alpha$ (PDB id: 1 A52) and ER- $\beta$ (PDB id: 5TOA). The docked pose of $\mathbf{1}$ and the co-crystalized pose of $17 \beta$-estradiol were superimposed in the active site of ER- $\alpha(\mathrm{A})$ and ER- $\beta(\mathrm{C})$. All atoms of the ligands and amino acid residues are colored by atom type: carbon atoms are colored green-blue (17 $\beta$-estradiol), orange (1), and grey (amino acid residues); nitrogen is blue; oxygen is red; sulfur is yellow; and hydrogen is white. The hydrogen bonds are indicated as green dashes and $\pi-\pi$ interactions as purple dashes. The docked pose of $\mathbf{1}$ in the ligand-binding pocket of ER- $\alpha$ (B) and ER- $\beta$ (D).

\section{Conclusions}

In the present study, the therapeutic potential of the isolated phenolic compounds (1-10) as phytoestrogens was investigated, where compound $\mathbf{1}$ was a newly isolated natural product, isoamericanoic acid B. In the E-screen assays, compounds 1, 2, and 10 displayed the estrogenic activities with 22.1 (1), 12.3 (2), and 6.9 (10) RPE values, respectively, suggesting that they may be useful as promising phytoestrogens for natural estrogen supplements. Additionally, the docking simulation results of compound 1, which exhibited the best estrogenic effects in MCF-7 BUS cells, showed interactions between compound 1 and the key residues of ER- $\alpha$ (Arg394, His524, Phe404) and ER- $\beta$ (Arg346, His475, Phe356) in their active binding sites. Compound 1 also exhibited slightly higher affinity for ER- $\beta$ than ER- $\alpha$ in the calculated Gibbs free energy for 1:ER- $\alpha$ and 1:ER- $\beta$. These results demonstrate that compound $\mathbf{1}$ from the bark of $A$. tegmentosum could be a promising phytoestrogen to alleviate menopausal symptoms.

Supplementary Materials: The following are available online at http:/ /www.mdpi.com/2072-6643/10/12/1915/ s1, Figure S1: The HR-ESIMS data of 1, Figure S2: The 1H NMR spectrum of 1 (CD3OD, $800 \mathrm{MHz}$ ). Figure S3: The 13C NMR spectrum of 1 (CD3OD, $200 \mathrm{MHz}$ ). Figure S4: The 1H-1H COSY spectrum of 1 (CD3OD). Figure S5: The HSQC spectrum of 1 (CD3OD). Figure S6: The HMBC spectrum of 1 (CD $\left.C_{3} O D\right)$. Figure S7: Re-docked pose of $17 \beta$-estradiol in the active site of ER- $\alpha$ and ER- $\beta$. Figure S8: Calculated Gibbs free binding energy for 1 and $17 \beta$-estradiol. Figure S9: The ${ }^{1} \mathrm{H}$ NMR spectrum of $2\left(\mathrm{CD}_{3} \mathrm{OD}, 800 \mathrm{MHz}\right)$. Figure S10: The ${ }^{1} \mathrm{H}$ NMR spectrum of $3\left(\mathrm{CD}_{3} \mathrm{OD}, 800 \mathrm{MHz}\right)$. Figure S11: The ${ }^{1} \mathrm{H}$ NMR spectrum of $4\left(\mathrm{CD}_{3} \mathrm{OD}, 800 \mathrm{MHz}\right)$. Figure S12: The ${ }^{1} \mathrm{H}$ NMR spectrum of $5\left(\mathrm{CD}_{3} \mathrm{OD}, 800 \mathrm{MHz}\right)$. Figure S13: The ${ }^{1} \mathrm{H}$ NMR spectrum of $6\left(\mathrm{CD}_{3} \mathrm{OD}, 800 \mathrm{MHz}\right)$. Figure S14: The ${ }^{1} \mathrm{H}$ NMR spectrum of $7\left(\mathrm{CD}_{3} \mathrm{OD}, 800 \mathrm{MHz}\right)$. Figure S15: The ${ }^{1} \mathrm{H}$ NMR spectrum of $8\left(\mathrm{CD}_{3} \mathrm{OD}, 800 \mathrm{MHz}\right)$. Figure S16: The ${ }^{1} \mathrm{H}$ NMR spectrum of $9\left(\mathrm{CD}_{3} \mathrm{OD}, 800 \mathrm{MHz}\right)$. Figure S17: The ${ }^{1} \mathrm{H}$ NMR spectrum of $10\left(\mathrm{CD}_{3} \mathrm{OD}\right.$, $800 \mathrm{MHz}$ ).

Author Contributions: Conceptualization, H.-J.P., H.-J.L., and K.H.K.; Formal Analysis, S.R.L., Y.J.P., Y.B.H., and J.C.L .; Investigation, S.R.L., Y.J.P., Y.B.H., and J.C.L.; Resources, H.-J.L.; Writing一Original Draft Preparation, 
S.R.L., Y.J.P., J.C.L., H.-J.P., H.-J.L., and K.H.K.; Writing-Review and Editing, S.R.L., S.L., and K.H.K.; Project Administration, H.-J.P., H.-J.L., and K.H.K.; Funding Acquisition, H.-J.L.

Funding: This work was carried out with the support of "Cooperative Research Program of Center for Companion Animal Research (Project No. PJ01398402)" Rural Development Administration, Korea.

Conflicts of Interest: The authors declare no conflict of interest.

\section{References}

1. Jia, M.; Dahlman-Wright, K.; Gustafsson, J. Estrogen receptor alpha and beta in health and disease. Best Pract. Res. Clin. Endocrinol. Metab. 2015, 29, 557-568. [CrossRef] [PubMed]

2. Hayashi, S.I.; Eguchi, H.; Tanimoto, K.; Yoshida, T.; Omoto, Y.; Inoue, A.; Yoshida, N.; Yamaguchi, Y. The expression and function of estrogen receptor alpha and beta in human breast cancer and its clinical application. Endocrine Relat. Cancer 2003, 10, 193-202. [CrossRef]

3. Shearman, A.M.; Karasik, D.; Gruenthal, K.M.; Demissie, S.; Cupples, L.A.; Housman, D.E.; Kiel, D.P. Estrogen receptor beta polymorphisms are associated with bone mass in women and men: The Framingham Study. J. Bone Miner. Res. 2004, 19, 773-781. [CrossRef] [PubMed]

4. Straub, R.H. The complex role of estrogens in inflammation. Endocrine Rev. 2007, 28, 521-574. [CrossRef] [PubMed]

5. Nanashima, N.; Horie, K.; Maeda, H. Phytoestrogenic activity of blackcurrant anthocyanins is partially mediated through estrogen receptor beta. Molecules 2018, 23, 74. [CrossRef] [PubMed]

6. Raheja, S.; Girdhar, A.; Lather, V.; Pandita, D. Biochanin A: Phytoestrogen with therapeutic potential. Trends Food Sci. Technol. 2018, 79, 55-66. [CrossRef]

7. Lee, W.; Ko, K.R.; Kim, H.; Lee, D.S.; Nam, I.; Lim, S.; Kim, S. Dehydrodiconiferyl alcohol inhibits osteoclast differentiation and ovariectomy-induced bone loss through acting as an estrogen receptor agonist. J. Nat. Prod. 2018, 81, 1343-1356. [CrossRef]

8. Yu, T.; Lee, J.; Lee, Y.G.; Byeon, S.E.; Kim, M.H.; Sohn, E.H.; Lee, Y.J.; Lee, S.G.; Cho, J.Y. In vitro and in vivo anti-inflammatory effects of ethanol extract from Acer tegmentosum. J. Ethnopharmacol. 2010, 128, $139-147$. [CrossRef]

9. Tung, N.H.; Ding, Y.; Kim, S.K.; Bae, K.H.; Kim, Y.H. Total peroxyl radical-scavenging capacity of the chemical components from the stems of Acer tegmentosum maxim. J. Agric. Food. Chem. 2008, 56, 10510-10514. [CrossRef]

10. Park, K.M.; Yang, M.C.; Lee, K.H.; Kim, K.R.; Choi, S.U.; Lee, K.R. Cytotoxic phenolic constituents of Acer tegmentosum maxim. Arch. Pharm. Res. 2006, 29, 1086-1090. [CrossRef]

11. Chang, B.Y.; Jung, Y.S.; Yoon, C.S.; Oh, J.S.; Hong, J.H.; Kim, Y.C.; Kim, S.Y. Fraxin prevents chemically induced hepatotoxicity by reducing oxidative stress. Molecules 2017, 22, 587. [CrossRef] [PubMed]

12. Kim, S.; Hur, S.J.; Kim, K.H.; Gi, K.S.; Whang, W.K. Antioxidant and anti-inflammatory compounds isolated from Acer tegmentosum. J. Med. Plant Res. 2012, 6, 3971-3976.

13. Liu, Q.; Shin, E.; Ahn, M.J.; Hwang, B.Y.; Lee, M.K. Anti-adipogenic activity of Acer tegmentosum and its constituent, catechin in 3T3-L1 cells. Nat. Prod. Sci. 2011, 17, 212-215.

14. Yu, J.S.; Moon, E.; Kim, K.H. A new cerebroside from the twigs of Lindera glauca (Sieb. et Zucc.) Blume. Bioorg. Chem. 2017, 74, 122-125. [CrossRef]

15. Shin, S.H.; Lee, S.R.; Lee, E.; Kim, K.H.; Byun, S. Caffeic acid phenethyl ester from the twigs of Cinnamomum cassia inhibits malignant cell transformation by inducing c-Fos degradation. J. Nat. Prod. 2017, 80, $2124-2130$. [CrossRef] [PubMed]

16. Lee, S.R.; Nam, J.W.; Kim, K.H. New triterpenoids from the stems of Cornus walteri. Chem. Pharm. Bull. 2017, 65, 683-686. [CrossRef] [PubMed]

17. Lee, S.R.; Moo, E.; Kim, K.H. Neolignan and monoterpene glycoside from the seeds of Pharbitis nil. Phytochem. Lett. 2017, 20, 98-101. [CrossRef]

18. Yu, J.S.; Roh, H.; Lee, S.; Jung, K.; Baek, K.; Kim, K.H. Antiproliferative effect of Momordica cochinchinensis seeds on human lung cancer cells and isolation of the major constituents. Braz. J. Pharmacogn. 2017, 27, 329-333. [CrossRef] 
19. Perez, P.; Pulgar, R.; Olea-Serrano, F.; Villalobos, M.; Rivas, A.; Metzler, M.; Pedraza, V.; Olea, N. The estrogenicity of bisphenol A-related diphenylalkanes with various substituents at the central carbon and the hydroxy groups. Environ. Health Perspect. 1998, 106, 167-174. [CrossRef]

20. Tanenbaum, D.M.; Wang, Y.; Williams, S.P.; Sigler, P.B. Crystallographic comparison of the estrogen and progesterone receptor's ligand binding domains. Proc. Natl. Acad. Sci. USA 1998, 95, 5998-6003. [CrossRef]

21. Souza, P.C.T.; Textor, L.C.; Melo, D.C.; Nascimento, A.S.; Skaf, M.S.; Polikarpov, I. An alternative conformation of ER $\beta$ bound to estradiol reveals $\mathrm{H} 12$ in a stable antagonist position. Sci Rep. 2017, 7, 3509. [CrossRef] [PubMed]

22. Wada, D.; Yasui, Y.; Tokuda, H.; Tanaka, R. Anti-tumor-initiating effects of phenolic compounds isolated from the bark of Picea jezoensis var. jezoensis. Bioorg. Med. Chem. 2009, 17, 6414-6421. [CrossRef] [PubMed]

23. Nguyen, P.; Yang, J.; Uddin, M.N.; Park, S.; Lim, S.; Jung, D.; Williams, D.R.; Oh, W. Protein tyrosine phosphatase 1B (PTP1B) inhibitors from Morinda citrifolia (Noni) and their insulin mimetic activity. J. Nat. Prod. 2013, 76, 2080-2087. [CrossRef] [PubMed]

24. Guz, N.R.; Stermitz, F.R. Synthesis and structures of regioisomeric hydnocarpin-type flavonolignans. J. Nat. Prod. 2000, 63, 1140-1145. [CrossRef] [PubMed]

25. Wang, Y.X.; Zhou, L.; Wang, J.; Lin, B.; Wang, X.B.; Huang, X.X.; Song, S.J. Enantiomeric lignans with anti- $\beta$-amyloid aggregation activity from the twigs and leaves of Pithecellobium clypearia Benth. Bioorg. Chem. 2018, 77, 579-585. [CrossRef] [PubMed]

26. Zhu, J.X.; Ren, J.; Qin, J.J.; Cheng, X.R.; Zeng, Q.; Zhang, F.; Yan, S.K.; Jin, H.Z.; Zhang, W.D. Phenylpropanoids and lignanoids from Euonymus acanthocarpus. Arch. Pharm. Res. 2012, 35, 1739-1747. [CrossRef]

27. Kim, J.; Kim, H.; Kim, S.; Lee, K.; Ham, I.; Whang, W. Antioxidative compounds from Quercus salicina Blume Stem. Arch. Pharm. Res. 2008, 31, 274-278. [CrossRef]

28. Jerezano, A.; Jimenez, F.; Carmen Cruz, M.; Montiel, L.E.; Delgado, F.; Tamariz, J. New approach for the construction of the coumarin frame and application in the total synthesis of natural products. Helv. Chim. Acta 2011, 94, 185-198. [CrossRef]

29. Hauer, H.; Germer, S.; Elsäßer, J.; Ritter, T. Benzopyranones and their sulfate esters from Pelargonium sidoides. Planta Med. 2010, 76, 350-352. [CrossRef]

30. Prachayasittikul, S.; Suphapong, S.; Worachartcheewan, A.; Lawung, R.; Ruchirawat, S.; Prachayasittikul, V. Bioactive metabolites from Spilanthes acmella Murr. Molecules 2009, 14, 850-867. [CrossRef]

31. Saitǒ, H.; Yokoi, M.; Aida, M.; Kodama, M.; Oda, T.; Sato, Y. ${ }^{13} \mathrm{C}$ NMR spectra of para-substituted methoxybenzenes and phenols in the solid state: Examination of chemical shift non-equivalence in ortho and meta carbons related to non-equivalent electron distribution, and application to assignment of peaks in meso-hexestrol and its derivatives. Magn. Reson. Chem. 1988, 26, 155-161.

32. Pan, S.M.; Ding, H.Y.; Chang, W.L.; Lin, H.C. Phenols from the aerial parts of Leonurus sibiricus. Chin. Pharm. J. 2006, 58, 35-40.

33. Bernet, A.; Seifert, K. A new approach to sesquiterpene arenes of the 9,11-drimenyl type (= [(1E,2RS,4aRS,8aRS)-octahydro-2,5,5,8a-tetramethylnaphthalen-1(2H)-ylidene $]$ methyl type). Helv. Chim. Acta 2006, 89, 784-796. [CrossRef]

34. Takaya, Y.; Furukawa, T.; Miura, S.; Akutagawa, T.; Hotta, Y.; Ishikawa, N.; Niwa, M. Antioxidant constituents in distillation residue of Awamori spirits. J. Agric. Food. Chem. 2007, 55, 75-79. [CrossRef] [PubMed]

35. Hill, D.A.; Crider, M.; Hill, S.R. Hormone therapy and other treatment for symptoms of menopause. Am. Fam. Physician 2016, 94, 884-889. [PubMed]

36. Moreira, A.C.; Silva, A.M.; Santos, M.S.; Sardao, V.A. Phytoestrogen as alternative hormone replacement therapy in menopause: What is real, what is unknown. J. Steroid Biochem. Mol. Biol. 2014, 143, 61-71. [CrossRef]

37. Ross, R.K.; Paganini-Hill, A.; Wan, P.C.; Pike, M.C. Effect of hormone replacement therapy on breast cancer risk: Estrogen versus estrogen plus progestin. J. Nat. Cancer Inst. 2000, 92, 328-332. [CrossRef]

38. Anandhi Senthilkumar, H.; Fata, J.E.; Kennelly, E.J. Phytoestrogens: The current state of research emphasizing breast pathophysiology. Phytother. Res. 2018, 32, 1707-1719. [CrossRef]

39. Kim, J.; Petz, L.N.; Ziegier, Y.S.; Wood, J.R.; Potthoff, S.J.; Nardulli, A.M. Regulation of the estrogen-responsive pS2 gene in MCF-7 human breast cancer cells. J. Steroid. Biochem. Mol. Biol. 2000, 74, 157-168. [CrossRef] 
40. Zhao, C.; Dahlman-Wright, K.; Gustafsson, J.A. Estrogen signaling via estrogen receptor (beta). J. Bio. Chem. 2010, 285, 39575-39579. [CrossRef]

41. Leung, Y.K.; Lee, M.T.; Lam, H.M.; Tarapore, P.; Ho, S.M. Estrogen receptor-beta and breast cancer: Translating biology into clinical practice. Steroids 2012, 77, 727-737. [CrossRef] [PubMed]

42. Oseni, T.; Patel, R.; Pyle, J.; Jordan, V.C. Selective estrogen receptor modulators and phytoestrogens. Planta Med. 2008, 74, 1656-1665. [CrossRef] [PubMed]

43. Campbell, S.; Whitehead, M. Oestrogen therapy and the menopausal syndrome. Clin. Obstet. Gynaecol. 1977, 4, 31-47. [PubMed]

(C) 2018 by the authors. Licensee MDPI, Basel, Switzerland. This article is an open access article distributed under the terms and conditions of the Creative Commons Attribution (CC BY) license (http://creativecommons.org/licenses/by/4.0/). 